\title{
Digital Technologies in Physical Culture and Sports Education
}

\author{
Skarzhinskaya E.N. \\ Federal Science Center of Physical Culture and Sport \\ Moscow, Russia \\ skar_e@mail.ru
}

\author{
Sarafanova E.V. \\ Federal Science Center of Physical Culture and Sport \\ Moscow, Russia \\ s5286@mail.ru
}

\begin{abstract}
Development of digitalization of all social and economic areas is a very fast process. Scientists and specialists in the field of physical culture and sports pay significant attention to the application of new approaches in physical and sports training, including the implementation of new technologies in various educational programs. Today, all regions, universities and schools with computer classes, interactive whiteboards and other multimedia equipment have the opportunity to use digital technologies and tools in educational goals. A large number of electronic educational resources, interactive environments, collections of video, audio resources, platforms-aggregators, automated information systems, etc. have been developed and successfully used in the education system. The article presents the results of the analysis of the computer games use in physical education classes (cyber-sports simulators based on the game motor activity of children). The use of the information and service platform of the Federal and regional digital educational environment in the implementation of various education programs in the field of physical culture and sports is analyzed. The results of monitoring digital technologies for physical education and sports education, their methodological development and pedagogical relevance, the results of the scientific papers analysis and consultations with experts at scientific conferences on the creation of pedagogical products based on digital technologies for mass educational programs of physical education and sports are presented. In the course of the empirical study, the priority directions of using modern software and hardware solutions in the lessons of physical culture, in the system of additional education and in the process of sports training are identified. The opportunities of digital technologies application with younger athletes are proved, the analysis of the developed digital technologies and methods of their use with older age of different groups of researchers is carried out.
\end{abstract}

Keywords-physical culture and sports education; digital technologies; digital competencies; physical culture; GTO (Ready for labor and defense complex); sports training, further education; cybersport; sports as norm of life.

\section{INTRODUCTION}

Information society formation conditions the need for all social spheres reformation and "physical culture and sport" sphere demands new approaches, especially in the sphere of new technologies realization in terms of branch educational programs (1, 4, 5 and others).

Digital technologies monitoring for physical culture and sport education, held in 2014-2019, showed that regardless of great amount of program and software solutions, there is poor methodical consideration and pedagogical need for them. Scientific works analysis and conversations with experts during scientific conferences showed that in terms of clear urgency of the considered topic, there are only some scientific research works and pedagogical products on the basis of digital technologies for mass educational physical culture and sport oriented programs. For example in 2019 the experiment was held in Federal Scientific Center of All-Russian Scientific Research Institute of Physical Culture concerning the use of the carried gadgets for "physical culture, sport and fitness" competence WorldSkills Russia.

Held by us research works showed that digital technologies are partially used in physical culture and sports education, however, this process is spontaneous and is not provided with normative-juridical acts.

The analysis of IT-tools introduction in general education establishments of the Russian Federation can be divided into two parts. In the first case IT-tools is used not directly during educational process realization, but during organizationaltechnical and administrative support.

As the held analysis showed, almost all regions have the system of education management automation. The following services are used: electronic registers and diaries; services of methodical support for teachers, which give an opportunity to use ready curriculum, subjects programs; aggregators of information resources, news lines, catalogues of useful resources (references); service of distant learning for general, professional and further education; libraries of electronic textbooks and manuals.

The opportunity to form and follow digital educational profile and individual educational plan creation and realization using federal information-service platform of digital educational environment in terms of further general educational programs realization in the sphere of physical culture and sport nowadays is not presented by any platform. 


\section{RESEARCH METHODOLOGY}

In general and further physical culture and sport education digital technologies can be used for the following purposes:

* Dynamic indices of functional systems reaction to the load (worn gadgets and specialized programs);

* psycho-emotional state improvement among those, who train (smart floor and smart wall technologies);

* motor activity competitions organization with the help of sensory controller technologies (analog products to Just Dance (3) computer game and etc.);

* didactic materials creation and allocation at open resources (Moscow electronic school and etc.).

For example, gadgets and specialized programs use was tested by producers in two leading higher educational establishments of Russia - federal state autonomous educational establishment of higher education First Moscow State Medical University named after I.M. Sechenov of the Ministry of Health and Moscow State Technical University named after Bauman. Competition for students was held between two higher educational estbalishments according to the level of activity with additional diagnostics. The aims of the competitions were the following: students' motor activity increase, youth involvement into a healthy life style, students' self-control diary digitization.

\section{RESULTS}

The result of the project was general activity and working capacity increase in terms of physical load increase $(67 \%$ people), more than half of the participants $58 \%$ began to control their diet with the help of electronic diary of nutrition (8).

Motor activity competitions with the help of sensory controller technology (analog products to Just Dance (3) computer game) was held in 2018 by the Federal center of physical upbringing organizational-methodical support of Education and Science Ministry of Russia (FSBE "FCPUOMS") together with the Federal Institute of Education Development (FIED), Russian State University of physical culture, sport, youth and tourism (RSYPCSY\&T) and Ubisoft company. Schools from each federal region took part in the competitions. Preliminaries and regional finals were in Ulyanovsk (Privolzhskiy federal region FR), Kaliningrad (North-Western FR), Yessentuki (North-Caucasian FR), Nyagan (Ural FR), Rostov-on-Don (South FR), Aginsk (Siberian FR), Khabarovsk (Far-eastern FR) and Moscow (Central FR). The final was held in Moscow International Saloon of Education -2018 (MISE-2018).The experiment showed that interactive digital technologies use at physical culture lessons provides not only interest in the subject increase, but also non-productive nervous-psychic tension decrease among students, schoolchildren's functional state and adaptive processes of organism optimization.

At Moscow electronic school portal there are more than 34500 created didactic materials concerning "Physical culture" subject. However, as the analysis showed, almost
30000 of them are pictures, 2000 are the tests, less than 2000 are lessons plans and methodical materials and almost 1000 are interactive supplements in a form of audio and video files and quizes. Methodologies and manuals, which describe the opportunities to use trackers, gadgets and specialized programs at physical culture lessons are not presented on this resource. At Russian portal "Russian electronic school" only lectures and tests, mini-presentations (3-4 minutes) are presented. The following things are not presented: interactive digital resources, references to electronic educational resources collections (ERC), automated systems of tests for children's and teen-agers' sports orientation. They help to realize the test and estimate psycho-physiological, psychological characteristics, physical working capacity, morphological status and the level of physical qualities among children and teen-agers.

Nowadays the programs are created for 6-14 year-old children's sports abilities, inclinations and orientations determination concerning going in for the definite kind of sport on the basis of testing morphological status, psychophysiological and functional abilities of a child [6,7]. The program helps parents to know current level of child's psychophysical development and predict his development and children to choose the kind of sport, which develops his or her abilities most of all $[8,9,10,11]$.

Modern digital educational environment formation would help to realize the model of continuous education in the region, which would have a positive influence on educational emigration of the best students owing to net education and interaction, would help to prevent the most talented youth outflow into other regions.

Directly during sports training the range of digital technologies can be conditioned by the aims of the definite stage of sports training. At sports-preparatory and initial stage it is recommended to use mentioned above tools, however, the questions of the fixed indices administration should be specialized (depending on a chosen kind of sport). At the stage of sports improvement it is recommended to use worn gadgets non-stop, including the programs of taking into account nutrition and sleep regime. The stage of higher sports mastery in most kinds of sport is connected with digital technologies. Individual trajectories of sports training are corrected in terms of feedback. We can state that this process would improve and in the increased indices analysis artificial intellect technologies would be used.

The urgency of digital technologies use with growing athletes is considered by different groups of research workers, but the problem of their use with athletes adults are not discussed in scientific literature. There is an opinion that digital technologies are not necessary in work with pensioners. However, a questioner survey among the participants of "Moscow longevity" program (n- 418) revealed their high level of digital competencies. Almost all participants used social media (98\%) and had smartphones (76\%). More than half of respondents $(63 \%)$ know about fitness bracelets and know their average daily physical load. $34 \%$ consider themselves power users of computer programs and have the need for digital technologies use during going in for sport. 
in terms of systematic physical load. Humanbeing. Sport. Medicine. 2019, vol. 19,1 , pp. $77-82$

Physical culture educational programs monitoring for elderly people didn't reveal methodical approaches, which realize digital technologies in this or that aspect.

Is it possible to transfer from traditional systems of testing physical readiness into digital ones? Theoretically and technologically it is possible and it was demonstrated by timely labor collective (Matveev A.P., Seluyanov V.N., Novoselov M.A., Strelnikova I.V., Abulkhanova M.V. and others). Created by them model of estimation showed the possibility of physical and theoretical, psychological readiness digitized registration (tests were stitched into pop-down menu sensory visualizer). The attempts to realize this model in practice showed that in "physical culture and sport" sphere there are no normative-juridical conditions for this transfer realization (2), because there is no any document that states the opportunity to use sensory controllers at physical culture and sport lessons. Also the opportunity to use VR, AR and MR are not considered.

\section{CONCLUSION}

The held research work helps to form the following theses:

- $\quad$ in terms of varied digital solutions for physical culture and sports education there is no methodical manuals concerning their use;

- there is social need for digital technologies use for elderly people;

- $\quad$ there are no created normative-juridical acts and it prevents digital technologies use in physical culture and sports sphere in order to increase motor activity.

\section{References}

[1] Kodolova I.A., Fatkullov I.R., Galyautdinova L.R., Nikonova T.V., Miftakhov R.F. Information technologies in training specialists in physical culture and sport direction. Problems of modern pedagogical education. 2017, 57-5, pp. 127-134.

[2] Kukushkin A.A., Novoselov M.A. System model of physical readiness estimation among junior schoolchildren using sensory visualizers - In collection of works: Collection of works by students and young scientists of FSBEE HE "RSYPCSY\&T" material of scientific conferences among students and young scientists. 2014, pp. 70-71.

[3] [ Levitov A.V. E-sport dancing simulator JustDance - physical culture and sport education tool - In collection of works: Collection of materials of scientific conferences among bachelor degree and master's degree students, postgraduates and applicants of the Ministry of Sport of the Russian Federation; Moscow state academy of physical culture; Moscow regional Olympic academy. 2018, pp. 79-81.

[4] Masyagina N.V., Zyurin E.A. Informatization in the system of further professional education as the mechanism of educational process intensification. Bulletin of sports science. 2018, 2, pp. 55-58.

[5] Nopin S.V., Koryagin Yu.V. Software creation for sports characteristics study (by the example of "Time and spatial characteristics of a person explorer" computer program. Omsk scientific bulletin. 2003, 4(25), pp. 196-197.

[6] Nopin S.V. Information technologies in scientific-methodical support of sports training. Questions of functional training in professional sport. 2014, vol. 2, 1, pp. 245-252.

[7] Petrov P.K. Information competency as the base for professionalism formation among the future specialists in physical culture and sport. Physical culture: upbringing, education, training. 2010, 2, pp. 51-55.

[8] Zhigalo V.Ya., Litvin F.B., Bulavkina T.A., Dubogruzova I. A., Stanishevskaya T. I. Functional state of a child's organism objectivization
[9] Kuznetsova Z.M., Kuznetsov S.A., Ovchinnikov Yu.D., Golovko P.V. throwing among athletes. The Russian Journal of Physical Education and Sport. 2018, 13(2), pp. 44-51. DOI: 10.14526/02_2018_308.

[10] Alexsandr S. Kuznetsov. Russian Professor's meeting. Russian Journal of Physical Education and Sport. 2019, 14(1), pp. 17-22. DOI: DOI 10.14526/2070-4798-2019-14-1-18-24

[11] UTL: https://onetrak.ru/solutions/projects/healthsteps/ Analysis of the morphological-functional indices connection degree in 